\title{
Aplicación de las técnicas de Markowitz a la Comercialización de Productos Agrícolas
}

Application of Markowitz Techniques to the Marketing of Agricultural Products

\author{
Rodrigo Pérez Peña ${ }^{1}$
} ${ }^{1}$ Docente investigador Universidad Piloto de Colombia Ciudad, país.
Email: ingpepe@hotmail.com

\section{OPEN ACCESS}

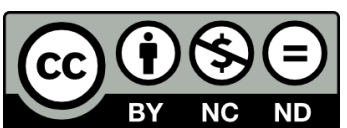

\section{Copyright:}

(02021. La revista Ingenierías USBmed proporciona acceso abierto a todos sus contenidos bajo los términos de la licencia creative commons Atribución no comercial SinDerivar 4.0 Internacional (CC BY-NC-ND 4.0)

Tipo de artículo: Investigación.

Recibido: 23-10-2020.

Revisado: 16-04-2021.

Aprobado: 12-05-2021.

Doi: $10.21500 / 20275846.5073$

Referenciar así:

R. Pérez Peña, "Aplicación de las técnicas de Markowitz a la Comercialización de Productos Agrícolas," Ingenierías USBMed, vol. 12, n. ${ }^{\circ}$, pp. 1-16, 2021.

\section{Disponibilidad de datos:}

todos los datos relevantes están dentro del artículo, así como los archivos de soporte de información.

\section{Conflicto de intereses:}

los autores han declarado que no hay conflicto de intereses.

Editor: Andrés Felipe Hernández. Universidad de San Buenaventura, Medellín, Colombia.
Resumen. Tradicionalmente la comercialización de compra y venta de los productos agrícolas que llegan al abastecimiento Corabastos, Bogotá D.C. al mayoreo y al detal sin la utilización de alguna técnica; que le permitan al inversionista realizar sus preferencias en su adquisición y al vender; allí se comercializa al destajo; donde impera el negocio de los mayorista e intermediarios, quienes establecen sus precios a los compradores interesados, estos mayoristas adquieren y luego venden a un mayor valor a los consumidores finales los artículos; que son el principal sustento de la canasta familiar de la capital y centro del país. El objetivo es experimentar como aplicar las técnicas de los modelos de selección de cartera de Markowitz, al comerciar la producción agrícola; que tan buena aplicación se han obtenido en el mercado bursátil.

Al final de la experimentación se logró como resultado, aplicar el modelo de selección de carteras de Markowitz a la comercialización de los productos de consumo doméstico y mejorar el actual sistema de comercializar estos mercados y a su vez poder brindar al inversionista, mejores alternativas que le permitan obtener unos óptimos rendimientos a un menor riesgo.

Palabras Clave. Portafolio, Rendimientos, Riesgo, Tenencia, Logarítmico, Matriz, Covarianza, Varianza.

Abstract. Traditionally the buy and sale commercialization of agricultural products that arrive at the Corabastos supply center in Bogotá D.C. it is made wholesale and retail without the use of any technique; that allows the investor to make their buy and sale preferences; there is a piece-rate commercialization; where prevails the market of the wholesalers and intermediaries, who establish their prices to the interested buyers, these wholesalers acquire and then sell to a greater value to the final consumers these products; that are the main sustenance of the capital and center of the country family basket. The objective is to experiment in how to apply the Markowitz portfolio selection model techniques, to the commercialization of agricultural products; The application that has been so well accepted in the stock market.

At the end of the experiment it was achieved as a result, to apply the portfolio model for Markowitz investment portfolios to the commercialization of those products for domestic consumption and to improve the current marketing system of these markets and at the same time be able to offer the investor, better alternatives that allows him to obtain optimal returns at a lower risk.

Keywords. Portfolio, Outputs, Risk, Holding, Logarithmic, Matrix, Covariance, Variance. 


\section{Introducción}

La presente investigación se realizó sobre la experimentación de las teorías de portafolios de inversión de Markowitz a la comercialización de los productos agrícolas.

Por lo general, las teorías de selección de carteras de Markowitz se han estudiado desde el punto de vista de los mercados bursátiles, sobre la base de una idea de la estructuración de un portafolio de inversión para ofrecer a los inversionistas que están interesados en invertir en acciones de renta variable o fija en la bolsa de valores del país, o del mundo; buscando la oportunidad de realizarlos de una manera diversificada, para lograr obtener la optimización de este, mediante la maximización del rendimiento y minimización del riesgo.

El problema de la comercialización de los productos agrícolas es la falta de una técnica apropiada que le permite al inversionista seleccionar la mejor opción para realizar su inversión y obtener altos rendimientos. El sistema actual que se utiliza es comercializar de forma tradicional mediante mayoristas y minoristas: los primeros son los que acaparan toda la producción que llega al centro de abastos de las diferentes regiones del país; estos, a su vez, los venden a los segundos a unos precios mayores, quienes a su vez los comercializan tanto a los distribuidores locales como a los otros negocios que trabajan y transforman los frutos para consumo familiar, a un valor más elevado.

Esta cadena de intermediarios es lo que hace que los inversionistas tengan que adquirir los productos a precios elevados y sus márgenes se reduzcan de tal manera que los distribuidores locales y negocios que los adquieren los encarezcan más, hasta llegar al consumidor final.

Otras de las dificultades en la comercialización de los productos agrícolas son la falta de garantías y altos riesgos en sus inversiones para compradores, ya que no cuentan con una organización debidamente estructurada, lo que hace que este expuesto a sufrir inconvenientes en la adquisición de estos; como en el manejo de los recursos financieros utilizados para su compra.

La informalidad del mercado de los productos agrícolas en su comercialización hace que el sector agrícola presente carencia de aplicaciones y de técnicas que le permitan apreciar con objetividad cuales serían sus beneficios en estos tipos de mercados, lo que hace, necesario buscar herramientas logren identificar mejores oportunidades de inversión.

Las características propias de los productos del sector agropecuario han permitido considerar que son bastante sensibles al riesgo, por la inestabilidad de precios y las cosechas; por tanto, mayor es la dificultad en la obtención de financiamiento de los proyectos para sus cultivos.

La gran variedad de productos agrícolas que produce el país en diferentes regiones con una variada esta- cionalidad y la intermediación en su adquisición, hacen acrecentar aún más la incertidumbre en los mercados para su compra, dificultando a las empresas interesadas y negocios en mantener una sostenibilidad en la producción de estos, ocasionando altos riesgos de incumplimiento con los demandantes y consumidores.

Los anteriores inconvenientes han motivado a la experimentación de las teorías de selección de cartera de Markowitz en la comercialización de los productos agrícolas, teniendo en cuenta la similitud de la información que posee el centro de Corabastos en la historia de sus precios de venta con los de cierre utilizados en la bolsa de valores.

El experimentar las teorías de Markowitz sobre portafolios de inversión y lograr que estas se puedan aplicar a la comercialización de los productos agrícolas, se tendría un avance muy significativo para el mercado de estos. En el contexto actual de la globalización de los mercados, la competencia económica internacional es cada día más intensa y abarca un número creciente de territorios que permiten pensar en lograr alcanzar estos. Dia tras día esta competencia ha llevado a los países emergentes a realizar intercambios comerciales a través de tratados de libre comercio (TLC), de los que el país tiene firmado una gran cantidad, donde se intercambia tecnología, productos procesados y no transformados, como de otras actividades de comercialización y de servicios.

"El comercio mundial de productos alimentarios continúa aumentando rápidamente, pero la estructura y las pautas del comercio difieren considerablemente según el producto y la región. Los factores fundamentales de la producción y la demanda, con inclusión del comercio y las políticas conexas, configuran estas pautas de diferentes formas, con implicaciones potencialmente importantes para la seguridad alimentaria [1].

En Colombia existe una entidad llamada "Corabastos" que es la encargada de organizar el mercado agropecuario de la ciudad de Bogotá y su área metropolitana, mediante el manejo de varias centrales mayoristas. A este centro de abastecimiento llega toda la producción agropecuaria de la región central del país, para ser comercializada con los diferentes sectores industriales y comerciales que requieren de estos productos. Siendo la ciudad de Bogotá la capital del país y donde se planifica las principales actividades socio económicas de las diferentes regiones de éste, siempre ha sufrido un proceso de desarrollo acelerado por la misma concentración de habitantes que posee, debido a estas circunstancias surge esta necesidad: "La concentración de casi tres millones de habitantes con que inició Bogotá la década de 1970 generó, entre otros problemas básicos, el de abastecimiento de alimentos en forma organizada y metódica. La infraestructura que existía era insuficiente y además generaba pérdidas y un manejo arbitrario 
de los precios. Las plazas públicas y los supermercados no daban abasto, y hasta las calles se acondicionaban para el mercadeo agropecuario" [2].

Es así como en 1970 se planificó la construcción de una central de abastos que diera el suministro de productos agrícolas necesarios para la ciudad; la asesoría de expertos de mercadeo de la Universidad de Michigan y de la Organización de las Naciones Unidas para la Alimentación y la Agricultura (FAO), aconsejaron al gobierno la necesidad de construir este tipo de abastecimiento para ciudades que tuvieran más de 150000 habitantes.

En 1972 se inauguraron las instalaciones de la Central de Abastos de la ciudad de Bogotá, con la funcionalidad que se detalla en la presente cita: "El 20 de julio de 1972, se inauguró la Central, y desde entonces es pionera en el área comercial agrícola del país. La Corporación de Abastos de Bogotá S.A.- CORABASTOS, es una Sociedad del orden nacional, de economía mixta vinculada al Ministerio de Agricultura y Desarrollo Rural, junto con la Gobernación de Cundinamarca y la Alcaldía de Bogotá, forman parte de los accionistas del sector oficial con un $47.92 \%$ del total de las acciones, y el $52.08 \%$ corresponde al sector del comercio. Su papel determinante dentro de la economía del país al fijar los precios de los principales productos agroalimentarios es difundido en un boletín diario a través de los diferentes medios de prensa escritos, hablados, orienta de manera adecuada las operaciones comerciales" [2].

Es la fuente primaria en cuanto a la información de los precios de los alimentos en el país, como puede verse en la anterior cita; otra entidad que maneja el comportamiento de productos agrícolas es el DANE, que realiza sondeos permanentes sobre la variación de estos en la canasta familiar. También existen otras entidades o medios de divulgación que se interesan por realizar seguimiento a los valores de dichos artículos que son básicos en la alimentación diaria de los habitantes y afectan directamente el bolsillo de los consumidores. Sin embargo, estas fuentes de información no influyen en el manejo interno de la comercialización de los productos agrícolas, y la central de abastos realiza su propia estrategia mediante mayoristas y minoristas sin ningún procedimiento técnico.

Actualmente, estos modelos de teorías de portafolios de Markowitz, vienen realizando experimentación en varios sectores económicos como la energía, salud, minería, infraestructura y agrícola a través de la bolsa agropecuaria, que está colaborando con los agricultores en una forma de intermediario financiero, mediante la financiación de las cosechas que realice este con contratos forward y derivados; sin embargo, en la comercialización de los diferentes productos agrícolas para consumo doméstico no se ha generado ningún sistema técnico de cómo realizar este mercado.
En México, el Ministerio de Agricultura y su secretaría de Agricultura, Ganadería Desarrollo Rural y Pesca y Alimentación vienen trabajando con la bolsa agropecuaria a través del CONVENIO NÚM. DGPRBS169/11 en el mejoramiento de la comercialización de la producción agrícola del país con la orientación en: "El ordenamiento del mercado y el uso de mejores instrumentos de comercialización requieren de la certeza que otorga un mercado de contratos agropecuarios adelantados (bolsa agropecuaria) con contratos estandarizados. Una bolsa agropecuaria para el país, con su respectiva Cámara de Compensación y Liquidación tendría como función primordial tomar los riesgos de incumplimiento entre los participantes del mercado, con lo que otorga certeza a los contratos de físicos y derivados, reduce los costos de transacción y permite el diseño de estrategias para la administración del riesgo" [3].

Existen otras aplicaciones en la parte agrícola como la diversificación del portafolio; se toma este principio para seleccionar que tipo de producto se debe sembrar según variación climatológica: "En el marco de las actividades agrícolas, la diversificación consiste en distribuir la inversión en distintos productos, de manera tal de evitar la concentración en una única actividad que condicione los resultados económicos al desempeño de esta. De esta forma, resulta posible reducir el riesgo al distribuirlo entre varias actividades, de tal modo que la evolución negativa de una de ellas pueda verse compensada por la evolución positiva de otras, obteniendo en promedio un nivel de riesgo más acotado" [4].

Es importante considerar la aplicabilidad en los commodities agrícolas y metales, como lo plantean Ramírez y Rodríguez: "En el momento de escoger los activos (en este caso commodities) que formarán un portafolio, los inversionistas no sólo se deben basar en los resultados históricos (esperando que continúe cierta tendencia), sino también estar atentos a las proyecciones sobre futuras utilizaciones como bienes sustitutos, que puedan incentivar el alza en los precios de los activos por el aumento en su demanda, lo cual generaría rentabilidades superiores que justifiquen la exposición al riesgo de dicha inversión" [5].

Aunque se han realizado varios documentos relacionados a la experimentación de las teorías de Markowitz a los mercados agrícolas, tan solo se han elaborado aplicaciones parciales a los fundamentos del modelo de selección de carteras en los portafolios de inversión en cuanto a siembras y planificación de cosechas, mas no para la comercialización.

El sector agrícola del país es uno de los sectores que viene sufriendo grandes transformaciones tecnológicas en la planificación y mejoramiento de los sistemas productivos como del control de plagas: "Farmapp es el nombre de la compañía de base tecnológica que le saca provecho a las aplicaciones móviles, el análisis de datos 
(Big Data) y el internet de las cosas (IoT) para impulsar la competitividad y el desarrollo del campo colombiano. Esta compañía ha desarrollado aplicaciones móviles, a partir de tecnología satelital y geolocalización, para monitorear las plagas, pronosticar el impacto del clima, evaluar la eficiencia de la fumigación y analizar las condiciones del suelo con el propósito de identificar el método de fertilización más efectivo" [6].

A pesar de ello nada se ha hecho por tecnificar la forma de comercialización la variedad de productos agrícolas que produce las diferentes regiones del país; de tal manera que se beneficie la cadena desde su origen hasta el consumidor final. Sin embargo, se tienen trabajos relacionando con la aplicación de las teorías de Markowitz tanto en el sector agrícola como en el financiero e industrial, en general, por ejemplo, el trabajo de Guillén Vidal [7] donde se aplicó la técnica de portafolios de inversión al control de plaguicidas en el cultivo de la papa se resalta lo siguiente: "Markowitz entiende que el inversor, en nuestro caso productor agrícola, es consciente de la contaminación por uso indiscriminado de agro-tóxicos, esperando altos niveles de rentabilidad, asimismo, espera que los niveles de riesgo (contaminación) alto sea indeseable. Para ello se vale del análisis media - varianza para obtener los niveles de minimizar la contaminación para los niveles de rentabilidad obtenidas" [7]. Se resalta la importancia de la aplicación de las técnicas de Markowitz para establecer el control de las plagas del cultivo de papa.

En el trabajo de Díaz-Granados [8] se realizó una investigación aplicada a medir los riesgos de los contratos de opciones bajo incertidumbre, con las técnicas de portafolios de inversión bursátil.

Por otro lado, en la industria vinícola se tiene el trabajo de Díaz, Bernabéu y Olmeda: "En este sentido el modelo de selección de carteras de Markowitz supone una buena herramienta para la determinación de la composición final de la cartera de productos de una empresa, y se demuestra su eficacia al aplicarlo en una empresa vinícola de Castilla-La Mancha para determinar la composición de su cartera óptima de productos, así como conocer la conveniencia o no de incluir un nuevo producto en la misma" [9].

En los seguros agrícolas es importante la aplicación al trabajo, el seguro agrario y la programación de cultivos con restricciones de capital; cuyo modelo se aplicó la técnica de selección de carteras: "La planificación de cultivos en contextos de riesgo o del conocimiento del valor futuro de las variables económicas en términos de probabilidad, se ha desarrollado apoyándose en las técnicas de «selección de cartera», de Markowitz [7]. Aunque Markowitz formula su modelo (como caso particular de un modelo clásico de programación estocástica) en el campo de la teoría de la formación de una cartera de valores óptima, su planteamiento es aplicable a otros supuestos de la vida económica" [10].

\section{Materiales y Métodos}

Analizando los diferentes alcances que se pretendían de la investigación, se ha identificado que puede ser inicialmente exploratoria, con alcance descriptiva y enfoque cuantitativo; teniendo en cuenta que este tipo de análisis son poco estudiados hasta el momento y su característica, es analizar la conveniencia de establecer un proceso de comercialización de los productos agrícolas mediante la aplicación de las técnicas de selección de portafolios de inversión de Markowitz, la anterior argumentación esta soportada en la siguiente conceptualización. Considerando una investigación exploratoria como "el objetivo es examinar un tema o problema de investigación poco estudiado del cual se tiene muchas dudas o no se ha abordado antes" [11]. Y la investigación descriptiva: "Los estudios de la investigación descriptiva buscan especificar las propiedades, características y los perfiles de personas, grupos, comunidades, procesos objetos o cualquier otro fenómeno que se someta a un análisis. Es decir, pretenden medir o reunir información de manera independiente o conjunta sobre los conceptos o de las variables a que se refieren, esto es, su objetivo no es indicar como se relacionan estas" [11].

La segunda fuente de metodología de investigación consultada del autor Sergio Carrasco Díaz argumenta lo siguiente: "Investigación exploratoria se recoge la información pertinente sobre la factibilidad posibilidad y condiciones favorables para sus fines investigativos.

La investigación descriptiva. Nos dice y se refiere sobre las características y cualidades internas y externas, propiedades y rasgos esenciales de los hechos y fenómenos de la realidad en un momento y tiempo histórico concreto y determinado" [12].

La población objeto de la investigación se tomó de la clasificación que posee el centro de abastecimiento Corabastos, de las variedades de productos agrícolas que producen las diferentes regiones del país; de una manera subjetiva, en abastos se tiene actualmente clasificado en cuatro categorías, tubérculos, hortalizas, frutas y plátanos, como se detallan en la Tabla 1.

Tabla 1. Clasificación variedad de productos agrícolas

\begin{tabular}{|lc|}
\hline \multicolumn{1}{|c}{$\begin{array}{c}\text { Clasificación } \\
\text { según variedad }\end{array}$} & $\begin{array}{c}\text { Cantidad de productos } \\
\text { por variedad }\end{array}$ \\
\hline \hline Tubérculos & 12 \\
Hortalizas & 34 \\
Frutas & 49 \\
Plátano & 2 \\
Total, variedad & 97 \\
\hline
\end{tabular}


Tabla 2. Clasificación variedad de productos agrícolas

\begin{tabular}{|llll|}
\hline \hline Tubérculos & Hortalizas & Frutas & Plátano \\
\hline \hline Arracacha & Acelgas & Aguacate & Plátano Colicero \\
Papa criolla lavada & Ahuyama & Banano criollo & Plátano Hartón \\
Papa pastusa & Alcachofa & Banano Urabá & \\
Papa R12 industrial & Arveja verde & Breva & \\
Yuca armenia & Berenjena & Fresa & \\
Yuca llanera & Brócoli & Curuba san bernando & \\
Papa suprema & Calabaza & Guayaba & \\
Papa sabanera & Coliflor & Guanábana & \\
Papa tocarreña & Espinaca & Lulo & Total=2 \\
Total=9 & Total=9 & Total=9 & \\
\hline
\end{tabular}

Donde en total se tienen 97 variedades de productos; de esta población se tomó una muestra de nueve (9) por cada variedad: tubérculos, hortalizas, frutas y dos (2) de plátano, por la poca diversidad de estos de una manera selectiva y subjetiva como se indica en la Tabla 2, según clasificación del centro de abastecimiento.

De esta muestra se seleccionaron dos grupos: uno el de hortalizas y otro variado, compuesto por productos de las cuatro clasificaciones que posee el centro de abastecimiento, para experimentar si es posible implementar el modelo de selección de portafolios de Markowitz, a la comercialización de estos.

Definiéndose de la siguiente manera subjetiva:

Grupo hortalizas; Acelgas, Ahuyama, Alcachofa, Arveja Verde, Espinaca, Brócoli, Cebolla Roja, Calabaza, Habichuela; variado con; Aguacate, Banano Criollo, Guanábana, Arracacha, Papa pastusa y criolla, Yuca armenia, Plátano hartón, Ahuyama, Berenjena; se procede realizar la experimentación con las hortalizas; se tomó por cada variedad una muestra de 48 datos correspondiente a los años 2014, 2015, 2016, 2017, en razón a que en el centro de abastecimiento el historial de los precios de venta es mensual, ante la poca variabilidad que tiene periódicamente; sin tener en cuenta los efectos climáticos e indicadores macroeconómicos que los pueda afectar. A comparación de los de cierre de los activos bursátiles estos tienen influencia en la volatilidad de los mercados nacionales e internacionales por cambios que registran las bolsas de valores como consecuencia de la fluctuación de las monedas o tasas de interés financieros.

Con esta información de los valores de venta históricos se elabora la matriz de precios de cierre que se llamara así para asimilar a la que se utiliza en el modelo de selección de portafolios de inversión de Markowitz y que se forma diariamente de las acciones que en ese momento se tengan registrados en la bolsa, en los productos agrícolas son el valor que publica, cada mes, el centro de Corabastos en su sitio web.

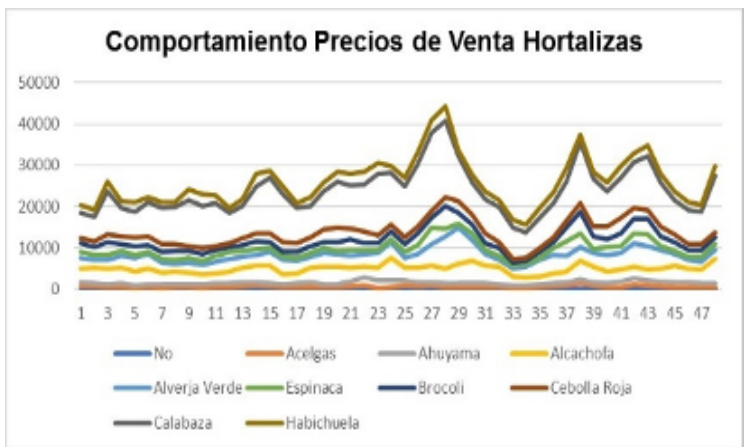

Figura 1. Comportamiento de los precios de ventas de las hortalizas

La tendencia de los precios presenta perturbaciones significativas en los productos Calabaza y la Habichuela con picos crecientes en el mes 27, el movimiento de los valores de las otras hortalizas seleccionada para la muestra tienen unas variaciones menos pronunciadas; son frutos muy apetecidos por un grupo selectivo de consumidores por su alto contenido nutritivo y especial en ciertos platos en los restaurantes de alta calidad, cuyo costo está permanentemente fluctuando al alza, además que por los efectos climáticos, hacen que sus cosechas bajen su producción, contribuyendo al incremento de estos. En el caso del grupo variado se tiene que el comportamiento de los precios de venta es el mostrado en la figura 2.

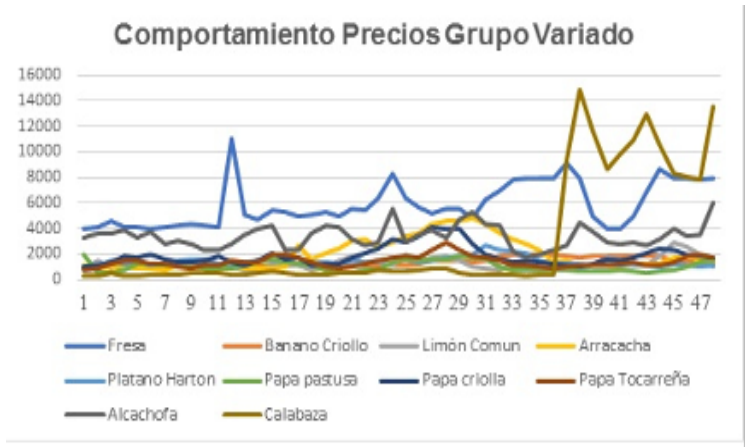

Figura 2. Comportamiento precios productos agrícolas 
Donde se registra un comportamiento bastante turbulento de los precios en la calabaza y la fresa. Esto se puede explicar debido a que la calabaza es un producto que por sus contenidos proteínicos en las dietas alimenticias viene siendo apetecido por un selecto grupo de consumidores; esta preferencia hace tener fluctuaciones significativas en su valor; la fresa es una fruta con característica similares, de ahí la alteración de este, además de la estacionalidad en sus cosechas. La matriz de rendimientos del grupo hortalizas y variado, es lo que rindió periódicamente un producto en el periodo analizado; esta tenencia es mensual, es decir una variación en largo a diferencia de las acciones que es corta, o sea diaria.

$\mathrm{Al}$ estimar la rentabilidad de un activo financiero en portafolios de inversión se tienen dos fórmulas muy importantes establecidas en el modelo de Markowitz; una es la simple o aritmética, resultado de una variación porcentual del precio del producto utilizado para ello de la siguiente manera:

$$
R_{j}=\frac{\text { Valor }_{\text {final }}-\text { Valor }_{\text {inicial }}}{\text { Valor }_{\text {inicial }}}
$$

Esta nos indica la variación de los precios de un periodo a otro, sin tener en cuenta los efectos del dinero en el tiempo. La rentabilidad logarítmica o capitalización compuesta continua, se calcula mediante la fórmula:

$$
R_{A}=\ln \left(\frac{P_{t}}{P_{t-1}}\right)
$$

que contiene la variación del dinero en el tiempo. Una interpretación a la diferencia, de expresión matemática se hará al responder la siguiente pregunta. ¿Cuál es la más conveniente a utilizar, una tasa logarítmica o la aritmética? En los mercados de capitales este interrogante se resuelve con las siguientes consideraciones: "Esta aproximación no parece ser problemática para periodos cortos de posesión de las acciones, pero definitivamente no será adecuada si se considera periodos largos de tenencia" [13]. Es de anotar que el rendimiento logarítmico es aproximadamente igual al cálculo del retorno aritmético es la tenencia corta; sin embargo, al emplearlo, trae ventajas y desventajas [13] y la más relevante es que la renta de un portafolio no corresponde al promedio ponderado de los rendimientos de cada uno de los productos y el simple es la media ponderada del redituar de los activos.

La ventaja del rendimiento logarítmico es ser aditivo; es decir, sus estimativos se pueden sumar en periodos cortos, días, semanas, quincenas.

Para el caso de la investigación se realizó la estimación del rendimiento de los portafolios por las dos formas: aritmética y compuesto continuo con el objeto de analizar las incidencias de estas modalidades. Los resultados del simple respecto a la compuesta van a diferir por su tiempo de tenencia; al tomar una decisión sobre cuál se recomienda, si el simple o continua, dependiendo de si los precios contienen perturbaciones ocasionadas por efectos internos o externos del entorno económico.

Aplicando las dos fórmulas para estimar los rendimientos de los diferentes productos que conforman los grupos hortalizas y variado, se obtiene la matriz de rentabilidades que conformarán los portafolios de experimentación. De estas se estiman los estadísticos estáticos, retorno promedio mensual, varianza y desviación estándar; como se detalla en la Tabla 3.

Se tiene un rendimiento promedio histórico del $4.82 \%$ durante los periodos analizados; el retorno más alto es para la espinaca con $10.58 \%$ y la habichuela con $6.19 \%$, el menor mensual es del $0.98 \%$ con la ahuyama. Existe una alta dispersión en los réditos simples de los productos por la misma fluctuación de sus precios, que se mueve en un rango de (48.28\%-16.56\%) bastante significativo.

Los estadísticos de los rendimientos logarítmicos son como se detallan en la Tabla 4; cuyos resultados son muy importantes considerando que estos representan la tasa de crecimiento del valor los productos.

La rentabilidad promedio de todos los productos es de $0.18 \%$; el comportamiento de los estadísticos de los rendimientos logarítmicos del grupo de hortalizas es las acelgas son el valor más negativo con $-0.66 \%$ y la Calabaza con un $1.70 \%$ positivo; esto demuestra que los precios de la muestra poseen una variación poco significativa; la dispersión de los datos con respecto de la media; se tiene que la Espinaca su fluctuación es alta con $46.07 \%$ según retorno y la de menor es la ahuyama con $15.48 \%$. Al analizar la información podemos observar que la tendencia de los retornos está orientada a una distribución normal; permitiendo aplicar las teorías de portafolios de Markowitz.

al aplicar el mismo procedimiento al grupo variado se tiene el siguiente comportamiento de los estadísticos estáticos en la Tabla 5.

Estos rendimientos simples son la ratio entre las pérdidas o ganancias en relación con lo invertido. Conocer la rentabilidad histórica es imprescindible para entender y comprender la evolución del activo en el tiempo y poder elaborar predicciones.

El rendimiento promedio histórico del $7.75 \%$ del grupo variado es bajo de acuerdo con la variedad de productos; comparado con la del retorno simple de las hortalizas, el más alto es la Calabaza con $49.95 \%$, el menor es del $0.69 \%$ banano criollo. Existe una incertidumbre en la información en los réditos por la misma fluctuación de sus precios, que se mueve en un rango de (312.29\%-7.01\%) muy relevante, donde la Calabaza tiene una alta volatilidad $312.29 \%$ mostrando con ello una significativa variación en la predicción de sus valores de venta. 
Tabla 3. Estadísticos de los rendimientos simples de las hortalizas

\begin{tabular}{|c|c|c|c|c|c|c|c|c|c|}
\hline & 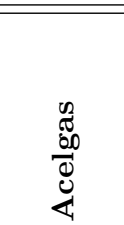 & 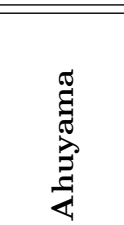 & 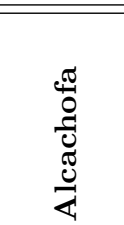 & 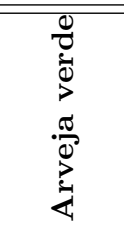 & 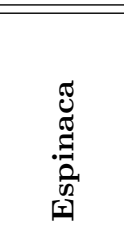 & 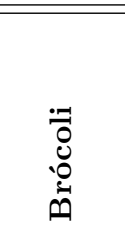 & $\begin{array}{l}\frac{\sigma}{0} \\
0 \\
0 \\
\frac{\pi}{二} \\
0 \\
0 \\
0 \\
0\end{array}$ & 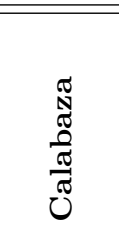 & 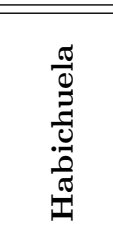 \\
\hline $\begin{array}{l}\text { Rentabilidad } \\
\text { promedio }\end{array}$ & $5.39 \%$ & $0.98 \%$ & $4.90 \%$ & $2.56 \%$ & $10.58 \%$ & $5.74 \%$ & $2.32 \%$ & $4.71 \%$ & $\bar{~} 6.19 \%$ \\
\hline Varianza & $12.77 \%$ & $2.74 \%$ & $7.96 \%$ & $6.50 \%$ & $23.31 \%$ & $15.45 \%$ & $5.12 \%$ & $6.72 \%$ & $11.17 \%$ \\
\hline $\begin{array}{l}\text { Desviación } \\
\text { estándar }\end{array}$ & $35.73 \%$ & $16.56 \%$ & $28.22 \%$ & $25.49 \%$ & $48.28 \%$ & $39.31 \%$ & $22.63 \%$ & $25.92 \%$ & $33.42 \%$ \\
\hline
\end{tabular}

Tabla 4. Estadísticos de los rendimientos logarítmicos de las hortalizas

\begin{tabular}{|c|c|c|c|c|c|c|c|c|c|}
\hline & $\begin{array}{l}0 \\
0 \\
00 \\
0 \\
0 \\
0 \\
0\end{array}$ & 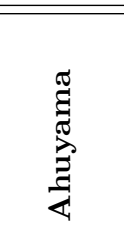 & 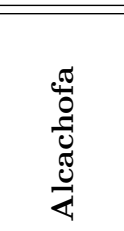 & 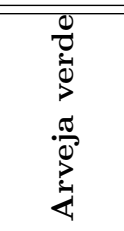 & 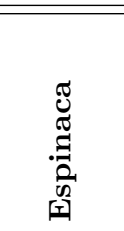 & 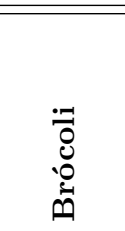 & 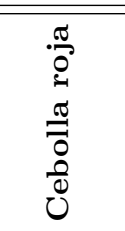 & 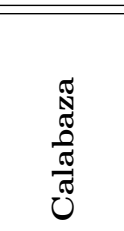 & 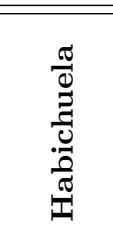 \\
\hline $\begin{array}{l}\text { Rentabilidad } \\
\text { promedio }\end{array}$ & $-0.66 \%$ & $-0.24 \%$ & $1.29 \%$ & $-0.63 \%$ & $0.34 \%$ & $-0.63 \%$ & $-0.15 \%$ & $1.70 \%$ & $0.59 \%$ \\
\hline Varianza & $12.68 \%$ & $2.40 \%$ & $7.28 \%$ & $6.68 \%$ & $21.22 \%$ & $12.50 \%$ & $5.12 \%$ & $5.91 \%$ & $11.91 \%$ \\
\hline $\begin{array}{l}\text { Desviación } \\
\text { estándar }\end{array}$ & $35.62 \%$ & $15.48 \%$ & $26.97 \%$ & $25.85 \%$ & $46.07 \%$ & $35.36 \%$ & $22.62 \%$ & $24.31 \%$ & $34.52 \%$ \\
\hline
\end{tabular}

Tabla 5. Estadísticos rendimientos simples grupo variado

\begin{tabular}{|c|c|c|c|c|c|c|c|c|c|c|}
\hline & 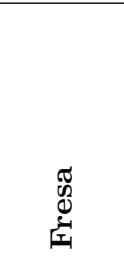 & 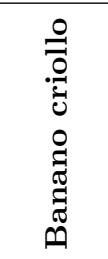 & 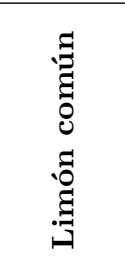 & 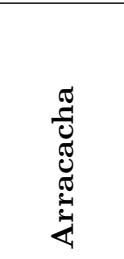 & 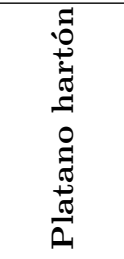 & 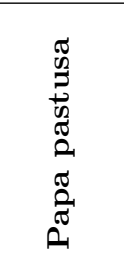 & 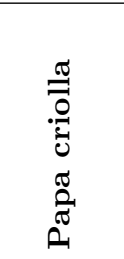 & 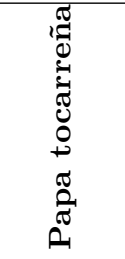 & 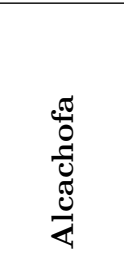 & 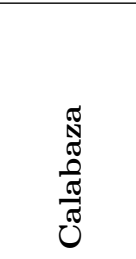 \\
\hline $\begin{array}{l}\text { Rentabilidad } \\
\text { promedio }\end{array}$ & $4.38 \%$ & $0.69 \%$ & $4.62 \%$ & $3.50 \%$ & $1.08 \%$ & $2.26 \%$ & $2.99 \%$ & $3.12 \%$ & $4.90 \%$ & $49.95 \%$ \\
\hline Varianza & $8.54 \%$ & $0.49 \%$ & $10.27 \%$ & $9.62 \%$ & $1.53 \%$ & $5.08 \%$ & $3.68 \%$ & $3.27 \%$ & $7.96 \%$ & $975.25 \%$ \\
\hline $\begin{array}{l}\text { Desviación } \\
\text { estándar }\end{array}$ & $29.22 \%$ & $7.01 \%$ & $32.05 \%$ & $31.01 \%$ & $12.39 \%$ & $22.53 \%$ & $19.18 \%$ & $18.07 \%$ & $28.22 \%$ & $312.29 \%$ \\
\hline
\end{tabular}

Tabla 6. Estadísticos rendimientos logarítmicos grupo variado

\begin{tabular}{|c|c|c|c|c|c|c|c|c|c|c|}
\hline & 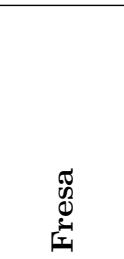 & 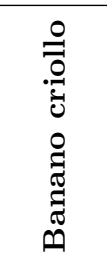 & 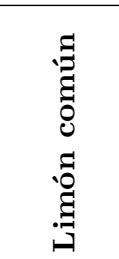 & 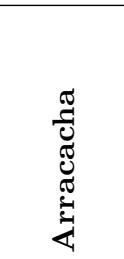 & 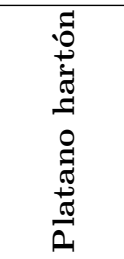 & 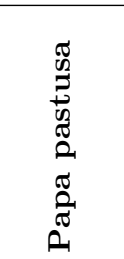 & 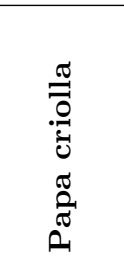 & 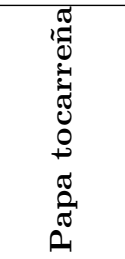 & 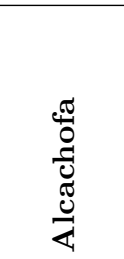 & 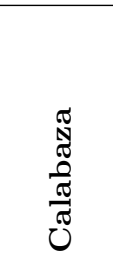 \\
\hline $\begin{array}{l}\text { Rentabilidad } \\
\text { promedio }\end{array}$ & $1.45 \%$ & $0.46 \%$ & $0.16 \%$ & $0.36 \%$ & $0.33 \%$ & $-0.67 \%$ & $1.22 \%$ & $1.58 \%$ & $1.29 \%$ & $8.08 \%$ \\
\hline Varianza & $5.38 \%$ & $0.47 \%$ & $8.75 \%$ & $5.53 \%$ & $1.52 \%$ & $6.94 \%$ & $3.59 \%$ & $3.04 \%$ & $7.28 \%$ & $26.25 \%$ \\
\hline $\begin{array}{l}\text { Desviación } \\
\text { estándar }\end{array}$ & $23.20 \%$ & $6.87 \%$ & $29.59 \%$ & $23.52 \%$ & $12.32 \%$ & $26.34 \%$ & $18.95 \%$ & $17.45 \%$ & $26.97 \%$ & $51.23 \%$ \\
\hline
\end{tabular}


El comportamiento de los diferentes parámetros estadísticos del grupo, se describen a continuación; se tiene que el promedio de los rendimientos que varía entre $8.08 \%$ de la Calabaza y $-0.67 \%$ de la papa pastusa, un rango no significativo donde los retornos medios de los 10 productos seleccionados en la muestra mantienen una tendencia central. El reditual histórico 1.43\% de los frutos lo que significa una disminución muy alta de su rentabilidad histórica en igual forma para todas las variedades consideradas en relación con el simple. Como se detalla en la tabla 6 .

El producto que presenta una mayor dispersión es la calabaza según su desviación estándar con el 51.23\% y la de menor concentración, banano criollo con $6.87 \%$. $\mathrm{Al}$ analizar los resultados se puede apreciar que los rendimientos logarítmicos o capitalización continua es la tasa de crecimiento del valor de los productos que guarda cierta parte simétrica. Al establecer varias pruebas con otros frutos del grupo; esta fue la que se obtuvo un mejor comportamiento para el manejo de los portafolios de experimentación. Esto indica el comportamiento irregular de los precios de estos productos durante los años 2014, 2015, 2016, 2017 como consecuencia de la inestabilidad en los hábitos de consumo.

En cuanto a la dispersión de los rendimientos, se midieron según desviación estándar; entendiendo esta como: "la desviación Estándar, en un conjunto de datos (precios en el caso del mercado de valores) es una medida de dispersión, que nos indica cuánto pueden alejarse los valores respecto al promedio (media), por lo tanto es útil para buscar probabilidades de que un evento ocurra, o en el caso del mercado bursátil, determinar entre qué rango de precios puede moverse un determinado activo, y determinar qué tipo de activos pueden ser más volátiles que otros" [14].

Al comparar las dispersiones de los dos grupos, tanto con tasas simples o aritméticas como la compuesta continua, podemos afirmar que el grupo de hortalizas correspondiente a una sola variedad de productos, la dispersión promedio de sus rendimientos periódicos con la tasa simple $30.62 \%$ y compuesta continua $29.64 \%$ y su diferencia es mínima a pesar de su tenencia; el variado cuya diversificación esta conformada por todas las variedades tiene una variación de $51.20 \%$ a la valoración aritmética y $23.64 \%$ con tasación logarítmica, significando ello que cuanto más sea diversificado el portafolio, su turbulencia con respecto a una línea central es más alta.

Estos estadísticos nos indican cuál fue el comportamiento de esos rendimientos, según la información histórica de sus precios de venta de los productos seleccionados, para elaborar el portafolio experimental de las hortalizas y grupo variado.

Uno de los principios básicos de la teoría de los portafolios es la diversificación y esta consiste en distribuir la inversión en diferentes productos, donde al inversionista se le recomienda, como dice el dicho popular "no se debe poner los huevos en una sola canasta"; con el fin de que al sufrir pérdidas en un producto por cualquier situación adversa del mercado estas sean compensadas con otro del portafolio; al diversificarlo también se pretende obtener una máxima rentabilidad a un menor riesgo.

El modelo de selección de portafolios de inversión de Markowitz, para controlar los riesgos asociados al portafolio son el sistemático y no sistemático: el primero es el riesgo del mercado y es por factores internos y externos de la economía, por problemas orden social, por cambios políticos a nivel nacional e internacional, lo que no se pueda solucionar con una diversificación de activos financieros bursátiles, los cuales serían agrícolas; significando que es no diversificable. El segundo, es aquel ocasionado internamente, diferente de los económicos, estatales o sociales: son aquellos que provienen de innovación tecnológica, la competencia, los paros y las malas acciones administrativas; al ser característico de una acción, lo es también para un artículo del agro, lo que hace posible que las adversidades de estos sean compensadas por los de otra firma lo que se llamaría diversificado. En el caso de los frutos, la adversidad de un producto puede ser asumido por otro según variedad. El riesgo es el llamado no sistemático, no es eliminado totalmente; al aumentar más activos en el portafolios, se logra disminuir este. Esto ocurre en los de inversión bursátil; la investigación busca establecer si igual situación suele ocurrir al aplicar a un portafolio de productos agrícolas.

En la elaboración del modelo de portafolio para la comercialización de los productos agrícolas según las teorías de Markowitz es necesario estimar ciertos parámetros muy importantes con el fin de medir la incertidumbre que poseen los precios de los artículos que participaran en la cartera, como son la matriz de covarianzas, de varianzas, de correlación, la volatilidad, las betas y la frontera eficiente. Según Markowitz, el inversionista debe ver la tasa de rendimientos asociada a los portafolios como variables aleatorias: "Markowitz afirma que los inversionistas deben basar sus decisiones de selección de portafolios solamente en rendimientos esperados y desviaciones estándar, dado que el rendimiento esperado se puede ver como la recompensa potencial asociada con el portafolio y la desviación estándar se puede ver como una medida del riesgo del portafolio" [15].

Una de las medidas clásicas de la estadística para el riesgo en los portafolios de inversión es la desviación estándar llamada volatilidad, porque identifica aquellos momentos en que el mercado presenta turbulencias y aumenta la incertidumbre de los activos participantes en el portafolio. 
Tabla 7. matriz varianza covarianza grupo hortalizas con tasa simple

\begin{tabular}{|cccccccccc}
\hline & \multicolumn{7}{c}{ Matriz de covarianzas } & & \\
& 1 & 2 & 3 & 4 & 5 & 6 & 7 & 9 \\
\hline 1 & $12.49 \%$ & $1.18 \%$ & $2.42 \%$ & $-0.80 \%$ & $6.52 \%$ & $2.35 \%$ & $-0.34 \%$ & $1.11 \%$ & $-1.34 \%$ \\
2 & $1.18 \%$ & $2.69 \%$ & $-0.30 \%$ & $0.54 \%$ & $0.11 \%$ & $0.19 \%$ & $0.02 \%$ & $-0.38 \%$ & $0.17 \%$ \\
3 & $2.42 \%$ & $-0.30 \%$ & $7.79 \%$ & $-0.12 \%$ & $1.04 \%$ & $1.91 \%$ & $0.97 \%$ & $1.74 \%$ & $-2.22 \%$ \\
4 & $-0.80 \%$ & $0.54 \%$ & $-0.12 \%$ & $6.36 \%$ & $0.24 \%$ & $1.62 \%$ & $0.71 \%$ & $1.34 \%$ & $-0.13 \%$ \\
5 & $6.52 \%$ & $0.11 \%$ & $1.04 \%$ & $0.24 \%$ & $22.81 \%$ & $3.25 \%$ & $0.23 \%$ & $1.05 \%$ & $3.44 \%$ \\
6 & $2.35 \%$ & $0.19 \%$ & $1.91 \%$ & $1.62 \%$ & $3.25 \%$ & $15.12 \%$ & $2.61 \%$ & $4.04 \%$ & $3.89 \%$ \\
7 & $-0.34 \%$ & $0.02 \%$ & $0.97 \%$ & $0.71 \%$ & $0.23 \%$ & $2.61 \%$ & $5.01 \%$ & $1.04 \%$ & $1.32 \%$ \\
8 & $1.11 \%$ & $-0.38 \%$ & $1.74 \%$ & $1.34 \%$ & $1.05 \%$ & $4.04 \%$ & $1.04 \%$ & $6.58 \%$ & $2.18 \%$ \\
9 & $-1.34 \%$ & $0.17 \%$ & $-2.22 \%$ & $-0.13 \%$ & $3.44 \%$ & $3.89 \%$ & $1.32 \%$ & $2.18 \%$ & $10.93 \%$ \\
\hline
\end{tabular}

1: Acelgas; 2: Ahuyama;3: Alcachofa;4: Alverja Verde; 5: Espinaca; 6: Brocili; 7: Cebolla Roja; 8: Calabaza; 9 : Habichuela.

Tabla 8. Matriz varianza covarianza grupo hortalizas con tasa logarítmica

\begin{tabular}{|cccccccccc}
\hline & \multicolumn{7}{c}{ Matriz de covarianzas } & & \\
& 1 & 2 & 3 & 4 & 5 & 6 & 7 & 8 \\
\hline \hline 1 & $12.41 \%$ & $0.69 \%$ & $2.44 \%$ & $-1.39 \%$ & $6.80 \%$ & $2.87 \%$ & $-0.15 \%$ & $1.24 \%$ & $-1.47 \%$ \\
2 & $0.69 \%$ & $2.34 \%$ & $-0.19 \%$ & $0.70 \%$ & $0.18 \%$ & $0.03 \%$ & $0.06 \%$ & $-0.38 \%$ & $-0.08 \%$ \\
3 & $2.44 \%$ & $-0.19 \%$ & $7.12 \%$ & $0.21 \%$ & $1.15 \%$ & $2.18 \%$ & $1.04 \%$ & $1.25 \%$ & $-2.89 \%$ \\
4 & $-1.39 \%$ & $0.70 \%$ & $0.21 \%$ & $6.54 \%$ & $0.08 \%$ & $1.02 \%$ & $0.92 \%$ & $1.29 \%$ & $-0.32 \%$ \\
5 & $6.80 \%$ & $0.18 \%$ & $1.15 \%$ & $0.08 \%$ & $20.77 \%$ & $3.95 \%$ & $-0.67 \%$ & $1.79 \%$ & $3.48 \%$ \\
6 & $2.87 \%$ & $0.03 \%$ & $2.18 \%$ & $1.02 \%$ & $3.95 \%$ & $12.24 \%$ & $1.77 \%$ & $4.12 \%$ & $3.87 \%$ \\
7 & $-0.15 \%$ & $0.06 \%$ & $1.04 \%$ & $0.92 \%$ & $-0.67 \%$ & $1.77 \%$ & $5.01 \%$ & $0.57 \%$ & $0.85 \%$ \\
8 & $1.24 \%$ & $-0.38 \%$ & $1.25 \%$ & $1.29 \%$ & $1.79 \%$ & $4.12 \%$ & $0.57 \%$ & $5.79 \%$ & $2.14 \%$ \\
9 & $-1.47 \%$ & $-0.08 \%$ & $-2.89 \%$ & $-0.32 \%$ & $3.48 \%$ & $3.87 \%$ & $0.85 \%$ & $2.14 \%$ & $11.66 \%$ \\
\hline
\end{tabular}

1: Acelgas; 2: Ahuyama;3: Alcachofa;4: Alverja Verde; 5: Espinaca; 6: Brocili; 7: Cebolla Roja; 8: Calabaza; 9: Habichuela.

Tabla 9. Matriz de varianza covarianza grupo variado simple

\begin{tabular}{|lcccccccccc|}
\hline \hline & 1 & 2 & 3 & 4 & 5 & 6 & 7 & 8 & 9 & 10 \\
\hline \hline 1 & $8.36 \%$ & $-0.06 \%$ & $-1.21 \%$ & $1.01 \%$ & $0.25 \%$ & $-0.12 \%$ & $-0.56 \%$ & $0.97 \%$ & $0.77 \%$ & $3.82 \%$ \\
2 & $-0.06 \%$ & $0.48 \%$ & $-0.04 \%$ & $-0.34 \%$ & $0.12 \%$ & $-0.31 \%$ & $0.36 \%$ & $0.15 \%$ & $-0.49 \%$ & $-2.66 \%$ \\
3 & $-1.21 \%$ & $-0.04 \%$ & $10.05 \%$ & $0.32 \%$ & $-0.10 \%$ & $-1.01 \%$ & $1.54 \%$ & $0.61 \%$ & $-2.93 \%$ & $-11.35 \%$ \\
4 & $1.01 \%$ & $-0.34 \%$ & $0.32 \%$ & $9.41 \%$ & $0.13 \%$ & $0.29 \%$ & $0.32 \%$ & $0.25 \%$ & $-0.77 \%$ & $-1.66 \%$ \\
5 & $0.25 \%$ & $0.12 \%$ & $-0.10 \%$ & $0.13 \%$ & $1.50 \%$ & $0.04 \%$ & $-0.07 \%$ & $0.43 \%$ & $0.58 \%$ & $0.36 \%$ \\
6 & $-0.12 \%$ & $-0.31 \%$ & $-1.01 \%$ & $0.29 \%$ & $0.04 \%$ & $4.97 \%$ & $1.01 \%$ & $1.55 \%$ & $1.25 \%$ & $-0.09 \%$ \\
7 & $-0.56 \%$ & $0.36 \%$ & $1.54 \%$ & $0.32 \check{z} \%$ & $-0.07 \%$ & $1.01 \%$ & $3.60 \%$ & $1.37 \%$ & $0.18 \%$ & $-4.28 \%$ \\
8 & $0.97 \%$ & $0.15 \%$ & $0.61 \%$ & $0.25 \%$ & $0.43 \%$ & $1.55 \%$ & $1.37 \%$ & $3.20 \%$ & $-0.39 \%$ & $7.73 \%$ \\
9 & $0.77 \%$ & $-0.49 \%$ & $-2.93 \%$ & $-0.77 \%$ & $0.58 \%$ & $1.25 \%$ & $0.18 \%$ & $-0.39 \%$ & $7.79 \%$ & $7.36 \%$ \\
10 & $3.82 \%$ & $-2.66 \%$ & $-11.35 \%$ & $-1.66 \%$ & $0.36 \%$ & $-0.09 \%$ & $-4.28 \%$ & $7.73 \%$ & $7.36 \%$ & $954.50 \%$ \\
\hline
\end{tabular}

1: Fresa; 2: Banano Criollo; 3: Limón Común; 4: Arracacha; 5: Plátano hartón; 6: Papa pastusa; 7: Papa criollo; 8: Papa tocarreña; 9: Alcachofa; 10:Calabaza.

Como la investigación es la experimentación del modelo de portafolios de Markowitz se hace necesario la estimación de estos parámetros con el fin de medir la incertidumbre de los precios de venta y las rentabilidades de cada uno de los seleccionados para conformar el portafolio; con el fin de analizar la turbulencia de los activos en este caso los productos en la varianza y covarianza se separa el componente de desviación estándar j del parámetro coeficiente correlación ij. Al realizar la separación de las matrices de varianzas y covarianzas mediría la volatilidad de los elementos que conforman la cartera, mientras la matriz de correlaciones mide los cambios en la relación de los valores de los artículos.

$$
\operatorname{VarCov}=\left[\begin{array}{cccc}
\sigma_{11} & \sigma_{11} & \cdots & \sigma_{1 n} \\
\sigma_{21} & \sigma_{22} & \cdots & \sigma_{2 n} \\
\vdots & \vdots & \ddots & \vdots \\
\sigma_{n 1} & \sigma_{n 2} & \cdots & \sigma_{n n}
\end{array}\right]
$$


Tabla 10. Matriz de varianza covarianza grupo variado logarítmica

\begin{tabular}{|lcccccccccc|}
\hline \hline & 1 & 2 & 3 & 4 & 5 & 6 & 7 & 8 & 9 & 10 \\
\hline \hline 1 & $5.27 \%$ & $0.03 \%$ & $-0.79 \%$ & $0.75 \%$ & $0.21 \%$ & $-0.33 \%$ & $-0.16 \%$ & $0.66 \%$ & $0.46 \%$ & $0.57 \%$ \\
2 & $0.03 \%$ & $0.46 \%$ & $0.04 \%$ & $-0.18 \%$ & $0.10 \%$ & $-0.26 \%$ & $0.34 \%$ & $0.12 \%$ & $-0.47 \%$ & $0.06 \%$ \\
3 & $-0.79 \%$ & $0.04 \%$ & $8.57 \%$ & $0.63 \%$ & $-0.07 \%$ & $-1.70 \%$ & $1.30 \%$ & $0.55 \%$ & $-2.92 \%$ & $-3.28 \%$ \\
4 & $0.75 \%$ & $-0.18 \%$ & $0.63 \%$ & $5.42 \%$ & $0.35 \%$ & $0.66 \%$ & $0.54 \%$ & $0.55 \%$ & $-0.76 \%$ & $-1.26 \%$ \\
5 & $0.21 \%$ & $0.10 \%$ & $-0.07 \%$ & $0.35 \%$ & $1.49 \%$ & $-0.07 \%$ & $-0.14 \%$ & $0.37 \%$ & $0.43 \%$ & $0.19 \%$ \\
6 & $-0.33 \%$ & $-0.26 \%$ & $-1.70 \%$ & $0.66 \%$ & $-0.07 \%$ & $6.79 \%$ & $0.82 \%$ & $1.45 \%$ & $0.87 \%$ & $-0.36 \%$ \\
7 & $-0.16 \%$ & $0.34 \%$ & $1.30 \%$ & $0.54 \%$ & $-0.14 \%$ & $0.82 \%$ & $3.51 \%$ & $1.30 \%$ & $0.31 \%$ & $0.12 \%$ \\
8 & $0.66 \%$ & $0.12 \%$ & $0.55 \%$ & $0.55 \%$ & $0.37 \%$ & $1.45 \%$ & $1.30 \%$ & $2.98 \%$ & $-0.26 \%$ & $1.45 \%$ \\
9 & $0.46 \%$ & $-0.47 \%$ & $-2.92 \%$ & $-0.76 \%$ & $0.43 \%$ & $0.87 \%$ & $0.31 \%$ & $-0.26 \%$ & $7.12 \%$ & $2.19 \%$ \\
10 & $0.57 \%$ & $0.06 \%$ & $-3.28 \%$ & $-1.26 \%$ & $0.19 \%$ & $-0.36 \%$ & $0.12 \%$ & $1.45 \%$ & $2.19 \%$ & $25.69 \%$ \\
\hline
\end{tabular}

1: Fresa; 2: Banano Criollo; 3: Limón Común; 4: Arracacha; 5: Plátano hartón; 6: Papa pastusa; 7: Papa criollo; 8: Papa tocarreña; 9: Alcachofa; 10:Calabaza.

Como el coeficiente de correlación es igual a:

$$
\rho_{i j}=\frac{\sigma_{i j}}{\sigma_{i} \sigma_{j}}
$$

entonces, la matriz de correlación es:

$$
\text { Correlación }=\left[\begin{array}{cccc}
1 & \rho_{12} & \cdots & \rho_{1 n} \\
\rho_{21} & \rho_{22} & \cdots & \rho_{2 n} \\
\vdots & \vdots & \ddots & \vdots \\
\rho_{n 1} & \rho_{n 2} & \cdots & 1
\end{array}\right]
$$

Esta descomposición permite trabajar sobre la matriz de la varianza y covarianza tomando valores obtenidos por la volatilidad condicional estocástica, entendiendo esta como "una medida de la intensidad de los cambios aleatorios o impredecibles en la rentabilidad o en el precio de un título; en la representación gráfica de una serie histórica de rendimientos se asocia la volatilidad con la amplitud de las fluctuaciones del rendimiento tanto es que se consideren en valor absoluto como en desviaciones alrededor de un valor medio" [16].

Esta volatilidad es la relacionada con los rendimientos de los precios de las acciones y cuyas fluctuaciones son causadas por factores no asimétricos y provenientes de las situaciones internas de las empresas y con su entorno. En los retornos obtenidos de los valores de los productos agrícolas, estas variaciones consideradas no asimétricas en los mercados financieros; son ocasionados por dos tipos de incertidumbre: uno, causado por los movimientos de las actividades agropecuarias y las económicas, en el caso del primero son el clima, estacionalidad, costos postcosecha, transporte, entre otros; y en el segundo por los macroeconómicos.

En este caso, trataremos la volatilidad del mercado que afecta directamente la comercialización de estos productos, considerando los otros que han permanecidos normales, y en nada afectará al realizar la experimentación de las teorías de selección de portafolios de Markowitz.
$\mathrm{Al}$ estimar la matriz de varianza covarianza como se indica en la Tabla 7, con la tasa simple.

Esta matriz de covarianzas nos mide las variables aleatorias como los rendimientos de los productos participantes en el portafolio, si se mueven juntas o están relacionadas entre sí. Por ejemplo, entre los precios de la alcachofa y las acelgas hay una relación de $2.42 \%$, significa que los retornos de esos dos tienden a moverse en la misma dirección. Un valor negativo indicando que la rentabilidad de los dos artículos se mueve en sentido contrario caso la arveja verde y las acelgas con $-0.80 \%$; un resultado bajo, cerca de cero, denotando que hay muy poca o ninguna afinidad, el rendimiento de la ahuyama y la cebolla roja, $0.02 \%$. Se dice que una covarianza cuando es positiva tiene una correlación creciente si la una sube la otra en lo hace en esa proporción, si es negativa indica que es decreciente: si una variable aumenta su pareja disminuye.

En el caso de la matriz de covarianzas, la relación mayor positiva se presenta entre los productos espinaca y acelgas con $6.52 \%$; la más negativa es hachuela y la alcachofa con $-2.32 \%$; se puede observar que un alto porcentaje de los artículos participantes en el portafolio que están relacionados entre sí es muy baja, indicando su independencia en el rendimiento, es decir que en nada influye el comportamiento del precio de estas para su retorno. Con la tasa logarítmica se tiene la Tabla 8:

La relación mayor positiva la poseen los productos espinaca y acelgas con $6.80 \%$, y las más negativas $2.89 \%$ entre habichuela y alcachofa; las perturbaciones de las dos matrices tienen variaciones poco significativas en su covarianza; en igual forma en su varianza. Como está en la Tabla 9 del grupo variado con tasa simple.

La relación más positiva es $7.73 \%$ entre calabaza y papa tocarreña y la negativa es $-11.34 \%$ entre calabaza y el limón común.

La matriz varianza covarianza del grupo variado logarítmico es como se detalla en la Tabla 10. 
La relación mayor positiva es $2.19 \%$ entre calabaza y alcarchofa y la más negativa es $-3.28 \%$ entre calabaza y el limón común. Las perturbaciones de las dos matrices respecto a su covarianza poseen diferencias de poca insignificanticas, en igual forma las varianzas.

A. Modelos de portafolios

Se plantean dos tipos de modelos de portafolios aplicando las teorías selección de carteras de Markowitz a la comercialización de los productos agrícolas para experimentar la utilización de estas en el mercado de estos. Uno para el grupo de las hortalizas y otro para el variado.

1. Grupo hortalizas: Este modelo de portafolio trata de medir según las teorías de la selección de portafolios de Markowitz cual sería la rentabilidad a menor riesgo que tendría un inversionista al realizar una inversión en esta variedad de productos.

2. Planteamiento matemático: El modelo matemático diseñado por Markowitz para obtener la optimización deseada como se presenta en la siguiente expresión:

$$
\operatorname{máx} E\left(R_{P}\right)=\sum_{j=1}^{n} w_{j} \times R_{j}
$$

C.S.R.

$$
\begin{aligned}
& \sigma_{P}^{2}=\sum_{i=1}^{n} \sum_{j=1}^{n} w_{i} \times w_{j} \times \sigma_{i j} \leq \sigma_{0}^{2} \\
& \sum_{j=1}^{n} w_{j}=1, \quad w_{j} \geq 0, \quad j=1,2, \ldots, n
\end{aligned}
$$

Se plantea un modelo de programación lineal cuya función objetivo a optimizar es de la forma minimización de la varianza o de la maximización del rendimiento del portafolio; sujeto a las siguientes restricciones; se multiplica vector de participación; por la covarianza y nuevamente por esté, menor igual a la medida de dispersión; además que la suma de los elementos de las proporcionalidades sea igual a 1; la condición de negatividad que todas variables sea mayores e igual a cero.

La forma matricial del anterior modelo es:

$$
\sigma_{P}^{2}=\left[\begin{array}{lll}
w_{1} & \cdots & w_{n}
\end{array}\right]\left[\begin{array}{cccc}
\sigma_{1}^{2} & \sigma_{12}^{2} & \cdots & \sigma_{1 n}^{2} \\
\sigma_{21}^{2} & \sigma_{2}^{2} & \cdots & \sigma_{2 n}^{2} \\
\vdots & \vdots & \ddots & \vdots \\
\sigma_{n 1}^{2} & \sigma_{n 2}^{2} & \cdots & \sigma_{n}^{2}
\end{array}\right]\left[\begin{array}{c}
w_{1} \\
w_{2} \\
\vdots \\
w_{n}
\end{array}\right]
$$

3. Matriz varianza covarianza: Este instrumento de medición llamando la matriz de varianza - covarianza que forman los productos mediante la rentabilidad; se estima el rendimientos simples y logarítmicos con el fin de determinar el riesgo, la volatilidad y la relación que poseen las diferentes variables que conforman el portafolio de hortalizas.

4. Modelo óptimo portafolio rendimientos simples grupo hortalizas: Un modelo básico de portafolio de los productos a comercializar de forma de los siguientes parámetros una rentabilidad esperada ponderada $\overline{R_{p}}$ cuya expresión matemática es:

$$
\overline{R_{p}}=w_{1} r_{1}+w_{2} r_{2}+\ldots+w_{n} r_{n}
$$

Donde $w_{i}$ es el porcentaje de participación en la actividad de inversión bajo la siguiente restricción $0 \leq$ $w_{i} \leq 1$ y $\sum_{i=0}^{n} w_{i=1} ;$ y $R_{i} ; i=1,2, \ldots, n$.

Significa esto que el rendimiento del $i$-esimo producto es una variable aleatoria con distribución normal, con media cero y variable continua; luego el rendimiento esperado del portafolio su expresión matemática:

$$
E\left(\overline{R_{p}}\right)=\sum_{i=1}^{n} w_{i} E(R)_{i}
$$

El riesgo asociado al portafolio está relacionado no solo con los productos que lo forman si no la que estos poseen entre sí. Esta relación la mide la covarianza de los rendimientos obtenidos de los frutos seleccionados en la cartera según sus correlaciones mediante la expresión matemática:

$$
\sigma_{i j}=\rho_{i j} \sigma_{i} \sigma_{j}
$$

donde los parámetros $\sigma_{i j}$ es la covarianza, $\rho_{i j}$ la correlación existente de los diferentes elementos y $\sigma_{i}$, $\sigma_{j}$ son las desviaciones estándar de los retornos de los precios de venta.

La varianza del portafolio con $n$ productos se define como:

$\sigma_{P}^{2}=\sum_{i=1}^{m} \sum_{j=1}^{n} w_{j} \sigma_{i j} w_{i}, i=1,2 \ldots, m, j=1,2 \ldots, n$.

donde $\sigma_{i j}$ la covarianza; la raíz cuadrada de la dispersión, $\sigma_{P}^{2}$, del rendimiento del $i$-esimo producto se denomina desviación estándar $\sigma_{P}$ es el indicador del riesgo, la cual indica que entre más grande sea esta, mayor es la incertidumbre que se tiene de invertir.

El modelo de portafolio, elaborado para la comercialización de los productos agrícolas estructurado con rendimientos simples su aplicación y resultados es el mostrado en los resultados. 


\section{Resultados}

La investigación experimental fue realizada con información estadística que reporta abastos sobre los diferentes precios promedios mensuales nominales de venta según peso de la variedad que se comercializa durante los años 2014, 2015. 2016, 2017 [17], dos muestras selectivas: una con el grupo hortalizas, acelgas, ahuyama, alcachofa, arveja verde, espinaca, brócoli, cebolla roja, coliflor, habichuela; la otra muestra de productos variados, conformada de las cuatro categorías en que las tiene clasificadas el centro de abastos (hortalizas, tubérculos, frutas, plátanos) así: fresa, banano criollo, limón común, arracacha, papa pastusa, criolla, tocarreña, plátano hartón, alcachofa, calabaza.

De las diferentes combinaciones que se realizaron se conformaron los dos portafolios: La elección de una estrategia de portafolio debe ser considerada con los objetivos de inversión, sin descuidar, obviamente, las necesidades de liquidez y la tolerancia al riesgo. La selección depende de la visión sobre la eficiencia del mercado, la tolerancia al riesgo y la naturaleza de los pasivos [5]. Finalmente, los grupos de productos hortalizas y variado para la investigación.

En los mercados financieros se tienen diferentes teorías sobre el comportamiento de los precios de las acciones, como consecuencia de la incertidumbre del entorno económico que los rodea, cuyas fluctuaciones periódicas hacen que el valor suba o baje en un momento dado. Esta situación no se registra en los precios de venta de los productos agrícolas: en los actuales momentos guardan una estabilidad periódica, que solamente se ve afectada por las variaciones de la canasta de bienes de consumo familiar, que se mide por medio del Índice de Precios al Consumidor (IPC).

En el análisis de los precios de venta de los productos se tomaron los mensuales que registra el centro de abastos y cuyas variaciones periódicas son muy lentas, lo que conlleva una tenencia larga para la presente experimentación, de un mes.

Es conveniente resaltar que, para la investigación se conformaron cuatro portafolios basados en los conceptos de rentabilidad simple y logarítmica, ante los efectos que estas producen en el comportamiento de las rentabilidades del portafolio y el riesgo, como en otros parámetros; teniendo en cuenta que son las dos formas más usadas para el calcula los rendimientos de las acciones en los mercados bursátiles.

El modelo de portafolio, elaborado para la comercialización de los productos agrícolas estructurado con rendimientos simples es donde en la columna de activos, se encuentran el total de productos (9) seleccionados para conformar el portafolio del grupo Hortalizas. La segunda columna es el vector resultante de los porcentajes de inversión que puede adquirir el inversionista en el portafolio de cada uno de los productos. Este porcentaje se estimó utilizando el software interno del Excel Solver. La columna de los rendimientos son los obtenidos en la matriz de rentabilidades y la columna es desviación estándar o volatilidad que posee cada activo con respecto al valor medio central ver Tabla 11.

Tabla 11. Modelo portafolio rendimientos simple grupo hortalizas

\begin{tabular}{|lccc|}
\hline \hline Activos & Participación Rendimiento & D.E \\
\hline Acelgas & $3.47 \%$ & $5.39 \%$ & $35.73 \%$ \\
Ahuyama & $39.14 \%$ & $0.98 \%$ & $16.56 \%$ \\
Alcachofa & $14.25 \%$ & $4.90 \%$ & $28.22 \%$ \\
Arveja Verde & $12.00 \%$ & $2.56 \%$ & $25.49 \%$ \\
Espinaca & $0.99 \%$ & $10.58 \%$ & $48.28 \%$ \\
Brócoli & $0.00 \%$ & $5.74 \%$ & $39.31 \%$ \\
Cebolla Roja & $13.71 \%$ & $2.32 \%$ & $22.63 \%$ \\
Coliflor & $6.74 \%$ & $4.71 \%$ & $25.92 \%$ \\
Habichuela & $9.69 \%$ & $6.19 \%$ & $33.42 \%$ \\
Total & $100.00 \%$ & & \\
& & & \\
Rendimiento & $2.92 \%$ & $41.19 \%$ & Anual \\
Portafolio & & & \\
Varianza & $1.11 \%$ & & \\
Portafolio & & & \\
Riesgo & $10.52 \%$ & & \\
Coeficiente & 0.277 & & \\
Variación & & & \\
\hline
\end{tabular}

El análisis de los resultados del portafolio de rendimientos simples, una vez realizada la corrida con el solver, es la columna de participación o ponderaciones: ponderaciones porcentuales son las que se recomiendan invertir de acuerdo a la teoría de portafolios [18] que corresponde al porcentaje que el inversionista puede fijar en el mercado de las hortalizas según portafolio: de las acelgas es $3.47 \%$, lo que significa que las condiciones de los precios y calidad son bajas en ese momento para comprar; ahuyama es $39.14 \%$, indicando que las posibilidades de colocar en este son muy buenas; alcachofa es $14.25 \%$, proporción a adquirir del artículo dado la atracción del consumidor, porque le va a contribuir a mantener la rentabilidad obtenida; arveja verde es $12.00 \%$, no es muy atractiva, sin embargo, contribuye a sostener el retorno en la cartera; cebolla roja es $13.71 \%$, que invirtiendo en el producto sus perspectivas se mantendría una ganancia aceptable; brócoli es $0.00 \%$, las expectativas de venta no son las mejores; calabaza es $6.74 \%$, la opción para invertir no es apropiada; habichuela es $9.69 \%$, las preferencias para el consumo por parte de los consumidores son aceptables; espinaca es $0.99 \%$, el fruto es menos atractivo para gastar en la inversión. El total de ponderaciones debe ser igual a 1. (Velez, 2003)

Con esta distribución, ¿cuál es la rentabilidad del portafolio y su riesgo? La rentabilidad es de $2.92 \%$ mes y $41.19 \%$ anual; este rendimiento del $2.92 \%$ sería lo 
que le retornaría a un inversor por invertir cierto capital en un mes; la varianza del portafolio es $1.11 \%$ y la volatilidad es de $10.52 \%$ mensual; en la teoría de Markowitz un inversionista puede aumentar su retorno a un mayor riesgo, esto sucede en las inversiones individuales; como se está analizando una cartera de productos (hortalizas), que correspondería a activos, "se presenta la posibilidad de reducir el riesgo mediante la diversificación de la tenencia accionaria, sin reducir correlativamente el rendimiento de las mismas" [18] y su coeficiente de variación es del 0.277; es "una medida más precisa para determinar la volatilidad del activo" [19], bastante atractiva teniendo en cuenta que son rendimientos simples.

Al aplicar la tasa compuesta continua el modelo de portafolios sus resultados son los mostrados en la siguiente Tabla:

Tabla 12. Modelo portafolio rendimientos logarítmico grupo hortalizas

\begin{tabular}{|lccc|}
\hline \hline Activos & Participación & Rendimiento & D.E \\
\hline \hline Acelgas & $4.31 \%$ & $-0.66 \%$ & $35.62 \%$ \\
Ahuyama & $41.35 \%$ & $-0.24 \%$ & $15.48 \%$ \\
Alcachofa & $14.30 \%$ & $1.29 \%$ & $26.97 \%$ \\
Arveja Verde & $8.26 \%$ & $-0.63 \%$ & $25.85 \%$ \\
Espinaca & $0.05 \%$ & $0.34 \%$ & $46.07 \%$ \\
Brócoli & $0.00 \%$ & $-0.63 \%$ & $35.36 \%$ \\
Cebolla Roja & $12.18 \%$ & $-0.15 \%$ & $22.62 \%$ \\
Calabaza & $8.94 \%$ & $1.70 \%$ & $24.31 \%$ \\
Habichuela & $10.61 \%$ & $0.59 \%$ & $34.52 \%$ \\
Total & $100.00 \%$ & & \\
& & & \\
Rendimiento & $0.20 \%$ & $2.43 \%$ & Anual \\
Portafolio & & & \\
Varianza & $1.00 \%$ & & \\
Portafolio & & & \\
Riesgo & $9.98 \%$ & & \\
Coeficiente & 0.020 & & \\
Sharpe & & & \\
\hline
\end{tabular}

Donde las participaciones disminuyen, como se puede apreciar en la Tabla 13, comparativa de las dos tasas.

La rentabilidad obtenida fue de $0.20 \%$ mes y $2.43 \%$ anual; la varianza es $1.00 \%$ y el riesgo es $9.98 \%$ y su coeficiente de variación es del 0.020; este es bastante significativo de un modelo a otro; es conveniente resaltar que la diferencia es consecuencia de la tenencia de los precios de venta que son mensual y las tasas logarítmicas solamente son utilizables para tenencias cortas de días, semanas. En la investigación se utilizaron los dos procedimientos, con el fin de analizar su impacto en la estimación de los portafolios. Al tomar la decisión de inversión se recomienda utilizar el de tasa simple o aritmética.
Tabla 13. Comparaciones de las participaciones

\begin{tabular}{|lcc|}
\hline \hline & Logarítimica & Simple \\
\hline Activos & Participación & Participación \\
\hline \hline Acelgas & $4.31 \%$ & $3.47 \%$ \\
Ahuyama & $41.35 \%$ & $39.14 \%$ \\
Alcachofa & $14.30 \%$ & $14.25 \%$ \\
Arveja Verde & $8.26 \%$ & $12.00 \%$ \\
Espinaca & $0.05 \%$ & $0.99 \%$ \\
Brócoli & $0.00 \%$ & $0.00 \%$ \\
Cebolla Roja & $12.18 \%$ & $13.71 \%$ \\
Calabaza & $8.94 \%$ & $6.74 \%$ \\
Habichuela & $10.61 \%$ & $9.69 \%$ \\
Total & $100.00 \%$ & $100.00 \%$ \\
\hline
\end{tabular}

Al estimar el portafolio con el grupo variado se obtuvieron los resultados que se muestran en la Tabla 14.

Tabla 14. Comparaciones de las participaciones

\begin{tabular}{|lcc|}
\hline \hline & Logarítimica & Simple \\
\hline Activos & Participación & Participación \\
\hline \hline Fresa & $2.67 \%$ & $3.43 \%$ \\
Banano criollo & $64.36 \%$ & $60.94 \%$ \\
Limón común & $5.98 \%$ & $7.01 \%$ \\
Arracacha & $4.60 \%$ & $5.18 \%$ \\
Plátano hartón & $6.95 \%$ & $7.39 \%$ \\
Papa pastusa & $7.72 \%$ & $6.09 \%$ \\
Papa criolla & $0.00 \%$ & $0.00 \%$ \\
Papa tocarreña & $0.00 \%$ & $0.00 \%$ \\
Alcachofa & $7.50 \%$ & $8.87 \%$ \\
Calabaza & $0.21 \%$ & $1.09 \%$ \\
Total & $100.00 \%$ & $100.00 \%$ \\
\hline
\end{tabular}

Al realizar la corrida del modelo con el grupo variado de productos agrícolas, se tiene que en la participación se producen variaciones significativas en algunos de estos como efecto de la diversificación de la cartera seleccionada de las cuatro variedades, (tubérculos, frutas, plátanos, hortalizas), cuyos precios de venta presentan fluctuaciones ante cambios en la degustaciones del consumo por parte de los consumidores finales; otro impacto es la tasa de rendimientos utilizada en la tenencia del precio. Los resultados de los parámetros se muestran en la Tabla 15.

Donde la rentabilidad del portafolio óptimo mensual es de $1.73 \%$ y anual de $22.78 \%$ mensual con tasa simple; de $0.55 \%$ mensual y $6.75 \%$ anual con tasa compuesta continua o logarítmica. Esta diferencia es bastante significativa para la decisión de invertir por parte de un inversionista; prefiriéndose la solución del portafolio simple. 
Tabla 15. Resultados portafolio óptimo

\begin{tabular}{|c|c|c|c|c|}
\hline & \multicolumn{2}{|c|}{ Portafolio simple } & \multicolumn{2}{|c|}{ Portafolio compuesto } \\
\hline Rendimiento Portafolio & $1.73 \%$ & $22.78 \%$ anual & $0.55 \%$ & $6.75 \%$ anual \\
\hline Varianza Portafolio & $0.23 \%$ & & $0.23 \%$ & \\
\hline Riesgo Portafolio & $4.82 \%$ & & $4.75 \%$ & \\
\hline Coeficiente Variación & 0.3575 & & 0.1150 & \\
\hline
\end{tabular}

La relevancia de realizar el cálculo por ambos métodos es poder comprobar si es posible la utilización de estos para la investigación sobre la aplicación de las teorías de portafolios de Markowitz en la comercialización de los productos agrícolas de consumo doméstico.

En el análisis de las hortalizas se encontraron valores positivos y negativos indicando, esto; que no es posible eliminar por completo el riesgo que posee el portafolio, y se busque disminuirlo mediante la diversificación de este. De igual forma se presenta para la muestra de los productos variados de las cuatro categorías. Estas variaciones son ocasionadas por las fluctuaciones en los precios de venta.

A. Análisis del portafolio óptimo según rendimientos Con los precios promedios mensuales del grupo hortalizas y variado, se calcularon la matriz de rendimientos, varianza, covarianza $\sigma_{i j}$, el vector de participación, el de retornos y de desviaciones estándar o riesgo de estos, dando como resultado los valores anteriormente indicados para cada portafolio.

\section{B. Rendimientos simples y logarítmicos}

Se tienen dos situaciones que se proponen en el experimento de las aplicaciones de las teorías de Markowitz a la comercialización de los productos agrícolas para los inversionistas, en las que se ha comprobado que sí se pueden implementar estas a este mercado. El resultado del portafolio experimental del grupo de hortalizas aplicando rendimientos simples fue el siguiente:

- Rendimiento del Portafolio 2.91\% mes y $41.11 \%$ anual; Varianza $1.11 \%$; riesgo $10.52 \%$; el coeficiente de variación 0.277 , donde se obtuvo una rentabilidad mensual de $2.91 \%$ y anual de $41.11 \%$ con una volatilidad amplia del $1.11 \%$ y un riesgo de $10.52 \%$ que correría el inversionista al realizar inversión en este portafolio con un coeficiente de variación del 0.277 significando la adversidad que corre por cada unidad de retorno.

Al desarrollar el portafolio con rendimientos logarítmicos se tiene los siguientes resultados:

- Coeficiente de variación 0.20.

- La rentabilidad del portafolio es de $0.02 \%$ mensual y $2.43 \%$ anual, su volatilidad total es de $1.00 \%$ y un riesgo de $9.98 \%$; coeficiente de variación 0.20 .

Cuando se analiza el comportamiento de los dos resultados se tiene que, al aplicar el rendimiento aritmético, se obtiene un mayor beneficio para el inversionista en relación con el de los retornos logarítmicos o tasa compuesta continua; resulta conveniente seleccionar el modelo de portafolio aplicando contribución simple.

En cuanto a la participación se tiene lo siguiente aplicando rendimientos simples es:

- Hortalizas; Acelgas 3.47\%; Ahuyama 39.14\%; Alcachofa 14.25\%; Arveja Verde 12.00\%; Espinaca 0.99\%; Brócoli 0.00\%; Cebolla Roja 13.71\%; Calabaza 6.74\%; Habichuela 9.69\%.

- Aplicando rendimientos logarítmicos; Acelgas 4.31\%; Ahuyama 41.35\%; Alcachofa 13.30\%; Espinaca 0.99\%; Arveja Verde 8.26\%; Cebolla Roja 12.18\%; Brócoli $0.00 \%$; Calabaza 8.94\%; Habichuela $10.65 \%$.

Donde se aprecian disminuciones en la participación de varios productos de las hortalizas, pero a su vez se obtienen opciones de compra en otros. Comparados los dos métodos se preferiría el portafolio simple, porque mejora la diversificación de la cartera y le da más alternativas de inversión al inversionista.

Analizando el portafolio variado se obtuvieron los siguientes resultados; el rendimiento fue de $1.725 \%$ mes y de $22.78 \%$ anual; varianza $0.23 \%$; el riesgo $4.82 \%$ mensual y un coeficiente de variaciones de 0.3575 .

La volatilidad total de los rendimientos es $0.23 \%$, muy bajo, significando que la fluctuación de los precios es normal durante el periodo analizado. El riesgo del portafolio es de $4.82 \%$, es moderado ante cambios del entorno; el coeficiente de variación es 0.3575 , indicando que por cada peso que reditúe 0.3575 centavos soportan las adversidades que se registren en la cartera.

En cuanto a los rendimientos logarítmicos del grupo variado se obtuvo lo siguiente:

- El rendimiento esperado del portafolio representa tan solo un $0.547 \%$, mensual y $6.76 \%$ anual, el riesgo $4.75 \%$; significa que la diversificación, al aplicar la función de optimización mínima, no produce una ganancia esperada superior a la que ofrece en un momento dado el mercado; el coeficiente de variación 0.1150 es bajo, lo que nos indica que por cada peso solamente 0.1150 centavos respaldan las adversidades del entorno.

La participación que ofrece este portafolio según tipo de rendimiento simple es el siguiente:

- En el portafolio variado; fresa $2.67 \%$; banano criollo $64.36 \%$, limón común $5.98 \%$, arracacha $4.60 \%$, plátano hartón $6.95 \%$, pastusa $7.72 \%$, criolla $0.00 \%$, tocarreña $0.00 \%$, Alcachofa $7.50 \%$, Calabaza $0.21 \%$. 
La participación del portafolio con rentabilidad logarítmica fue la siguiente:

- Portafolio variado: fresa 3.43\%; banano criollo $60.94 \%$, limón común $7.01 \%$, arracacha $5.18 \%$, plátano hartón $7.39 \%$, pastusa $6.09 \%$, criolla $0.00 \%$, tocarreña $0.00 \%$, alcachofa $8.87 \%$, calabaza $1.09 \%$.

En la aplicación de los rendimientos simples y logarítmicos es cuanto a rentabilidad del portafolio se más atractivo el simple que ofrece un retorno de $1.725 \%$ mensual y del $22.78 \%$ anual; con un riesgo $4.82 \%$ que es mínimo.

Es conveniente resaltar que la diversificación con los rendimientos simples es más atractiva que el rendimiento logarítmico.

La rentabilidad esperada del logarítmico fue de 0.547 $\%$ mensual y anual $6.76 \%$, con un riesgo del $4.75 \%$, lo que significa que la diversificación da una volatilidad mínima; no se produce una ganancia superior a la del mercado.

Como resultado final se tiene que, por ambos procedimientos, rendimientos simples y logarítmicos, se obtuvo que la aplicación de las teorías de Markowitz puede ser aplicables al mercado de los productos agrícolas de consumo doméstico; evitando así el problema de los intermediarios en la comercialización "en tanto que en los demás siguen requiriendo de diversos intermediarios, entre acopiadores, seleccionadores y distribuidores al por mayor, que son los que finalmente firman los contratos de abastecimiento con los supermercados" [20], que encarecen el valor de estos al consumidor final. Las diferencias en cuanto a participaciones de un modelo a otro son ocasionadas por la consideración de la tenencia de largo plazo de los precios de ventas de los productos.

En la incertidumbre de los rendimientos de los productos generados por los precios de venta, se puede apreciar a través de la covarianza existente entre ellos, además de su correlación suya relación es moderada en el modelo.

\section{Conclusiones}

Como resultado del presente trabajo de experimentar la aplicación de las técnicas de los modelos de selección de cartera de Markowitz a la comercialización de los productos agrícolas, que tan buena aceptación se han obtenido en el bursátil, obteniéndose que sí es posible implementar estas teorías de carteras al mercado agrícola del centro de abastos.

Ante los diferentes problemas que existen en la comercialización de los productos agrícolas, como consecuencia de la larga cadena de intermediarios que perjudica al consumidor final por el incremento que sufren los precios, una solución es el establecimiento de un sistema de oferta y demanda que se hace en el bursátil en su mercado de acciones.
Una vez realizada esta experimentación, es necesario realizar un análisis de las variables que afectan los valores de los productos agrícolas en su comercialización, teniendo en cuenta que las estadísticas existentes en el centro de abastos son muy limitadas por su organización; además de no poseer estudios que permitan analizar los efectos que causan en el mercado las fluctuaciones de los precios.

Como el modelo de optimización de selección de carteras de Markowitz que actualmente es utilizado en los mercados bursátiles le brinda al inversionista seleccionar su portafolio de tal manera que obtenga su máxima rentabilidad con el menor riesgo, estas mismas posibilidades podrán lograrse al implementar este sistema en la comercialización de estos productos, eludiendo el abuso desmedido de los intermediarios.

$\mathrm{Al}$ analizar el comportamiento de los precios de los productos seleccionados para la conformación de los portafolios, estos presentan pocas variaciones en comparación a los de las acciones que fluctúan mucho más en su tiempo de tenencia, por efectos tanto internos como externos de variables macroeconómicas y microeconómicas, además permanecen constantes en periodos largos que hacen que las fluctuaciones sean mensuales a diferencia de las del mercado bursátil, que es diario.

Los rendimientos obtenidos de los productos mediante el método de rendimiento simple y logarítmico permitieron analizar en las matrices de covarianza y correlación en cada modelo elaborado, que sus movimientos están relacionados y bien determinados.

\section{Referencias}

[1] Organización de las Naciones Unidas para la Alimentación y la Agricultura [FAO], El estado de los mercadosde productos básicos agrícolas. Comercio y seguridad alimentaria: lograr un mayor equilibrioentre las prioridades nacionales y el bien colectivo, El estado de los mercadosde productos básicos agrícolas. Comercio y seguridad alimentaria: lograr un mayor equilibrioentre las prioridades nacionales y el bien colectivo. Roma: FAO, 2015.

http://www.fao.org/3/i5090s/i5090s.pdf.

[2] Corabastos, "Nuestra Historia," 23 abril 2017. [Online]. Available: https://www.corabastos.com. co/en/nosotros.

[3] Secretaría de Agricultura y Desarrollo Rural [SAGARPA], Bolsa agropecuaria, Ciudad de México, 2017. https://www.gob.mx/cms/uploads/attach ment/file/255710/5TO_INFORME_2017_web .pdf.

[4] L. M. Pecar, Teoría de portafolio: utilización para evaluar los riesgos agropecuarios. Oficina de Riesgo Agropecuario, 2018. http://www.ora.gov. 
ar/archivos/Portafolios \%20Agricolas \%20Eficien tes.pdf.

[5] C. Ramírez Flórez y J. A. Rodríguez Gallego, "Estructuración de un portafolio," Soluciones de Postgrado EIA, n. ${ }^{\circ}$ 2, pp. 69-78, 2008. 15 de junio del 2008. https://repository.eia.edu.co/bitstr eam/handle/11190/631/RSO00015.pdf?sequenc $\mathrm{e}=1$.

[6] Redacción Semana, "Tecnología aplicada a la productividad del campo colombiano," Revista Semana, 18 de ene. de 2016. https://www.semana. com/actualidad/articulo/

tecnologia-para-mejorar-la-productividad-del-ca mpo-colombiano/218224/.

[7] L. A. Guillén Vidal, Impacto económico de la regulación ambiental en la producción de papa. Distrito Barranca. Región Lima, Lima: Universidad Nacional Agraria La Molina, 2015.

http://repositorio.lamolina.edu.pe/bitstream/ha ndle/UNALM/2109/H20-G844-T.pdf?sequence= 1\&isAllowed $=\mathrm{y}$.

[8] M. C. Díaz-Granados, La eficacia de los mercados de futuros en la protección del riesgo de precios para los productores de commities agrícolas, UNED. Universidad Nacional de Educación a Distancia, 2017. https://dialnet.unirioja.es/ser vlet/tesis? codigo $=173542$.

[9] M. Díaz, R. Bernabéu y M. Olmeda, "Aplicación del modelo de Markowitz para la determinación de la cartera eficiente de vinos en la empresa vinícola," Separata ITEA - Información Técnica Económica Agraria, vol. 103, n. ${ }^{\circ}$ 1, pp. 43-53, diciembre del 2007. https://www.aida-itea.org/aidaitea/files/itea/revistas/2007/103-1/43-53_ITEA 103-1.pdf.

[10] F. Muñoz Murgui, El seguro agrario y la programaciónde cultivos con restricciones de capital. https://documentacion.fundacionmapfre.org/do cumentacion/publico/i18n/catalogo_imagenes/ imagen_id.cmd?idImagen $=1061871$.

[11] R. Hernandez Sampieri and C. Fernandez Collado and M. D. P. Baptista Lucio, Metodología de la investigación, Quinta ed. Mexico: MaGrawHill, 2010.

[12] S. Carrasco Díaz, Metodología de la Investigación Científica. Editorial San Marcos, 2006.

[13] L. Berggrun y J. C. Alonso, Introducción al analisis de riesgo financiero, Tercera ed. Bogotá: Ecoe Ediciones, 2015.

[14] L. Mora, "Qué es la desviación estándar y cómo interpretarla \#1," 11 noviembre 2009. [Online]. Available: https://tradingcenter.wordpress.com/ 2009/11/11/que-es-la-desviacion-estandar-y-com o-interpretarla- $1 /$.

[15] S. M. Salinas, D. A. Maldonado y L. G. Díaz, "Estimación del riesgo en un portafolio de acti- vos," Apuntes del CENES, vol. XXIX, n. ${ }^{\circ}$ 50, pp. 117-150, 10 de agosto del 2010.

[16] M. D. Márquez Cebrián, Modelo setar aplicado a la volatilidad de la rentabilidad de las acciones: algoritmos para su identificación. Barcelona: Universitat Politècnica de Catalunya, 2002. http://hdl.handle.net/10803/6503.

[17] Corabastos, "Precios y tendencias," 2021. [Online]. Available: https://precios.precioscorabastos. com.co/\#/.

[18] H. Salas Harms, "La teoría de cartera y algunas consideraciones epistemológicas acerca de la teorización en las áreas económico-administrativas," Contaduría y Administración, n. ${ }^{\circ} 208$, pp. 37-52, enero del 2003. http://www.redalyc.org/articulo. oa? id $=39520803$.

[19] N. A. Gomero Gonzales and V. R. Masuda Toyofuku and S. Bazan Castillo, "Uso del coeficiente de correlación y desviación estándar en la selección de portafolios de activos financieros de renta variable," Quipukamayoc, vol. 25, n. ${ }^{\circ} 49,2017$. https://doi.org/10.15381/quipu.v25i49.14288.

[20] Redacción Portafolio, "Comercialización agrícola llena de intermediarios," Revista Portafolio, 20 de abril del 2021. https://www.portafolio.co/econ omia/finanzas/comercializacion-agricola-llena-int ermediarios-486692. 